\title{
Imagem-performada e imagem-atestação: o documentário brasileiro e a reemergência dos espectros da ditadura
}

\author{
Andrea França Martins \\ Patricia Machado
}

Resumo: A reivindicação da memória da Ditadura Civil-Militar no cinema brasileiro contemporâneo se intensifica. Este artigo retoma documentários da década de 1980, ideias e autores já explorados anteriormente para se ater à discussão do uso de depoimentos e imagens da época da ditadura na produção audiovisual recente e ainda seu modo de assumir performativamente a falta - de documentos, de memória, de imagens. Uma longa viagem e Que bom te ver viva (ambos de Lucia Murat), entre outros, serão analisados a partir dessas questões.

Palavras-chave: imagem de arquivo; imagem performada; ditadura; documentário.

Abstract: Performed image and image attestation: the Brazilian documentary and the reemerging specter of dictatorship - The vindication of the memory of the Civil-Military Dictatorship in contemporary Brazilian cinema intensifies. This article recollects documentaries of the 1980s, and ideas and authors that have been examined before in order to attain to discuss the use of testemonies and film footage from the period of the dictatorship on recent audiovisual production, and their mode of performatively assuming the lack - of documents, memory, and images. Uma longa viagem [A Long Journey] and Que bom te ver viva [How Nice to See You Alive], both by filmmaker Lucia Murat, will be analyzed, among others, from the standpoint of these issues.

Keywords: filed image; performed image; dictatorship; documentary.

Os filmes Uma longa viagem (Lucia Murat, 2011), Diário de uma busca (Flavia Castro, 2010), Elena (Petra Costa, 2013), Memória Para Uso Diário (Beth Formaggini, 2007), Utopia e barbárie (Silvio Tendler, 2009), Cidadão Boilesen (Chaim Litewski, 2009), 
Os dias com ele (Maria Clara Escobar, 2013), entre outros, são reveladores do momento atual do Brasil, onde se engendra, lentamente, a reivindicação pela memória dos vinte e um anos de Ditadura Civil-Militar, com a punição de crimes e de torturadores, com a abertura de arquivos secretos, com a restituição da verdade em torno dos desaparecidos e dos assassinados pela repressão política. Com a instalação da Comissão Nacional da Verdade, em maio de 2012, o debate sobre o significado dessa memória "revelada" ganhou um impulso inédito.

Se na produção cinematográfica documental da década de 1980, momento da abertura política no Brasil e em que o cinema começa a recuperar a memória visual e audiovisual dos anos da ditadura, o uso de imagens de arquivo e do testemunho desse período está associado às noções de atestação e ideologia, na produção documental contemporânea que foca o mesmo contexto, arquivos e depoimentos frequentemente estão na imagem para teatralizar a história.

São filmes que exploram as possibilidades performativas da memória histórica, permitindo ao espectador experimentar as imagens não de um modo único, mas como um processo lacunar onde elas só adquirem realidade na relação com o espaço da cena, através de uma concepção topográfica dos espaços da filmagem (FRANÇA, 2009). Tal concepção recoloca a questão da relação da imagem com o espectador ao explicitar que todos os espaços do filme são espaços de encenação - da intimidade, das relações sociais, da memória.

A partir, sobretudo de Uma longa viagem (2011) e Que bom te ver viva (1989), ambos de Lucia Murat, analisaremos o uso das imagens de arquivo (público, privado) e do testemunho, partindo da premissa de que o documentário dos anos 1980, o qual se debruçou sobre as imagens relativas ao período do regime militar, é um cinema que, embora heterogêneo, trabalha as imagens como prova histórica de um período que significou a suspensão democrática, a história interrompida da República no Brasil. Já parcela significativa da produção cinematográfica da última década, diferentemente, passa a assumir e explorar através dos gestos, das falas e dos movimentos do corpo dentro da cena - os anos da ditadura na forma da falta: falta de imagens, falta de documentos, falta de verdade, falta de memória.

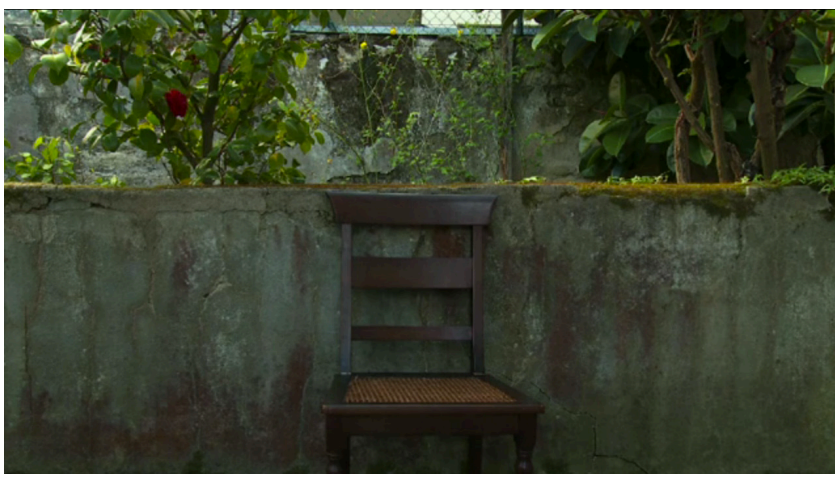

Fig. 1. Os dias com ele (Maria Clara Escobar) 
Na imagem, há uma cadeira vazia. Por trás da câmera, a documentarista Maria Clara insiste que seu pai, Carlos Henrique Escobar, leia um documento do Departamento de Ordem Política e Social (Dops) autorizando sua prisão. Ele se recusa veementemente, diz que não vai fazer "papel de bobo", que milhares de prisões políticas foram feitas nessa época, que solicitar dele tal leitura é uma tolice. O pai (intelectual, dramaturgo, filósofo) e a filha (diretora) discutem e se confrontam verbalmente fora do campo visual, enquanto vemos a cadeira vazia na qual o pai deveria sentar-se para ler o texto. O espaço da cena se constrói então nesse duelo sonoro, onde a cadeira expõe o desconforto desse lugar (do filme, do reencontro dos dois em Portugal), onde Carlos Henrique parece não querer estar, recusando-se em se adequar tanto às expectativas da filha como às da diretora.

O assento vazio solicita a entrada em cena de Maria Clara que, vencida pela autoridade intelectual e paterna, senta-se no lugar que seria dele para realizar a tarefa. Invadir o plano é expor não só a "derrota" da diretora na sua relação com o espaço da cena, mas também expurgar o silêncio e as lacunas em torno da memória da ditadura, teatralizando no corpo situações, afetos, intensidades. Como se a falta se revelasse na simples presença da cadeira vazia e na entrada em cena da documentarista, cujo corpo torna-se locus de falas, gestos, imagens, memórias do que foi e/ou do que poderia ter sido (Os dias com ele).

Em Os dias com ele, Uma longa viagem, Diário de uma Busca, Elena, as viagens pelas estradas do Brasil e do mundo surgem como pretexto para a evocação de uma difícil jornada do documentarista pelo espaço da cena e pelo tempo impuro da memória (DIDIHUBERMAN, 2003, p. 37). Não se trata de revelar nada, nenhuma verdade histórica, mas mostrar um corpo em situação e uma câmera atenta às sensações nele inscritas e que dão sentido à sua atuação; mostrar a possibilidade de que esse corpo possa se sustentar no espaço vazio da falta; mostrar as sobrevivências e os espectros que afetam cada gesto, cada movimento, cada palavra.

Se no documentário dos anos 1980, os testemunhos e as imagens de arquivo da ditadura cumprem a função de janela aberta para a história, nos documentários contemporâneos, frequentemente eles jogam com o espaço da cena, com uma teatralidade que não quer ser janela, mas quer expandir os sentidos. Entre o interstício frágil da carne, da fala e das imagens do passado, habitam redes de afeto, dizem esses filmes recentes, redes que jogam o espectador dentro de um universo familiar, íntimo (de filhos, pais, irmãos) e estranhamente opaco.

\section{Uma questão de sobrevivência}

Ao contrário do que sucedeu com os documentários brasileiros feitos para TV, na década de 1980, que se pautavam por mostrar que a recuperação da história e da memória recente do país não estava entre suas prioridades, ${ }^{1}$ os documentários, da mesma década,

1 Japão, uma Viagem no Tempo (1985, Walter Salles, Rede Manchete), América (1989, João Salles, Manchete), Angola (1988, Roberto Berliner, Rede Bandeirantes), African Pop (1989, Belizário Franca, Manchete). 
feitos para exibição nos cinemas se esforçam por assumir a função de constituir uma memória pública sob a forma de uma vinculação imaginária entre o novo contexto, em vias de democratização, e a história interrompida da República no país.

A década de 1980 é um momento de mudanças de cunho social, político e econômico, momento em que o país se reorganiza culturalmente, devido à Anistia e à recente finalização da ditadura militar (1985), momento da primeira eleição presidencial direta pós-abertura política. Jânio a 24 Quadros (1982, Luiz Alberto Pereira), Jango (1984, Silvio Tendler), Cabra Marcado pra Morrer (1984, Eduardo Coutinho), Céu Aberto (1985, João Batista de Andrade), Terra para Rose (Tetê Moraes, 1987), entre outros, trabalham com arquivos de cinejornais, dos jornais impressos, de imagens públicas e privadas dos anos 1960/1970, pensando a história recente (os anos da repressão) como momento de suspensão democrática, uma história interrompida que precisa se lembrada, sobretudo porque feita por sujeitos e gestos destinados à perpetuação. No campo da história política, vemos nas telas do cinema sujeitos como Juscelino, Tancredo, Jânio; no campo da história dos homens infames, surgem os personagens do prisioneiro político, do torturado, do operário e do camponês precarizados, porém mobilizados pelas lutas ideológicas da época.

Que bom te ver viva, realizado no final dos anos 1980, constitui-se através dos depoimentos de oito ex-presas políticas aliados à interpretação da atriz Irene Ravache que, nesse filme, funciona como um desdobramento da cineasta e das personagens entrevistadas. O filme participou de diversos Festivais Internacionais ${ }^{2}$, mas foi durante o Festival de Cinema de Brasília que alcançou seu apogeu, quando ganhou os prêmios de Melhor filme do júri popular, do júri oficial e da crítica, entre outros. ${ }^{3}$ Aliado a isso, seu lançamento, no final de 1989, teve uma importância cultural e política, pois sua consagração se deu em um Festival ocorrido na capital do país às vésperas das eleições do primeiro presidente da República escolhido por voto direto, após o término da ditadura.

Mais do que descrever e enumerar sofrimentos, o filme mostra a experiência dessas mulheres que sobreviveram lúcidas aos experimentos brutais da tortura. Murat opta por gravar os depoimentos delas em vídeo, com o enquadramento semelhante ao de um retrato $3 \times 4$, enquanto seus cotidianos, após quase duas décadas, são filmados com luz natural; para os monólogos da personagem de Ravache, o filme constrói uma cenografia teatral, onde a presença da atriz e o enquadramento frontal da câmera aludem a um palco. A todo o momento o filme recorre às imagens de jornais da década de 1970 cujas manchetes relatam em tom espetaculoso as ações de grupos guerrilheiros ("terroristas"), assim como às fotos das depoentes na imprensa, ainda jovens, e em álbuns de família.

Irene Ravache faz a pergunta que norteia toda a narrativa: “(...) ao invés de por que sobrevivemos seria importante perguntar como sobrevivemos?". A memória da luta armada

2 Festival de Mujeres (Buenos Aires, 1990), San Francisco Film Festival (1990), Manheim Festival (Alemanha, 1990), Human Rights Festival (NY, EUA, 1991), Yamagata Film Festival (Japão, 1991).

3 Ainda, de Melhor Montagem (Vera Freire) e Melhor Atriz (Irene Ravache). 
e da tortura é o cerne do filme. Explorar a conexão entre o passado recente e o presente parece fazer parte tanto da proposta do filme como do espírito cinematográfico da época.

Em Jango, a alusão à luta pela anistia, já no final, aparece como paradigma de um reencontro da nação com seus heróis civis excluídos pela direita vencedora em 1964. Em Cabra Marcado, o balanço dos anos de ditadura enquadra num mesmo referencial existencial a derrota de intelectuais, dos estudantes, dos operários, dos camponeses. A experiência da perda passa a unir a todos. Em Jânio a 24 quadros, a alusão à Lei da Anistia de 1979 ganha um tom jocoso na narração em voz over que enfatiza seu caráter conciliador assim como seu gesto de apagamento de um passado de abusos e violações aos direitos humanos.

Se, para sobreviver, foi preciso passar uma borracha, não falar e não lembrar, Que bom te ver viva demonstra que, para aqueles que foram presos e torturados, só existiram duas saídas: a loucura ou a lucidez do sobrevivente. Se quem enlouquece tem direito à internação, de quem sobrevive, cobra-se o esquecimento. A memória da tortura constrange, silencia, apieda. Como coloca Gagnebin, a imposição do esquecimento se dá como "um gesto forçado de apagar e de ignorar, de fazer como se não houvesse havido tal crime, tal dor, tal trauma, tal ferida do passado" (2010, p. 170).

Para o militante que sofreu a tortura e/ou aquele que teve que fugir de seu país, o esquecimento se torna uma estratégia de sobrevivência, a maneira possível de expurgar a memória da dor e da humilhação. Como uma espécie de gesso por meio do qual a vida, limitada, pode prosseguir, o esquecimento torna-se um modo de exílio no tempo e no espaço.

Que bom te ver viva mostra, contudo, que a tortura não pode ser esquecida facilmente. A filmagem propicia a ocasião e a câmera funciona como estímulo para que as depoentes rememorem e atestem que, apesar de tudo, conseguiram manter seu espírito de luta e sua dignidade, graças justamente à coragem de deixar à mostra os traumas passados. Como destacou, à época, o cineasta Eduardo Escorel no Jornal do Brasil, o filme explora "o dilema dilacerante das vítimas da tortura: de um lado, a tentação de esquecer; de outro, a descoberta de que para sobreviver é preciso não esquecer nunca" (22 de outubro de 1989).

A força dramática do filme provém, sobretudo dos rostos das oito sobreviventes, em vigorosos closes, que exibem ecos de seu próprio espanto diante da capacidade de continuarem vivas e de acreditar que ainda há sentido. Em outra matéria da época, do Jornal O Globo, Ely Azeredo diria que o filme "põe em jogo questões como a alienação, a fuga pelo esquecimento, a omissão" e que ainda assim "o passado reflui", mesmo quando "as feridas se interiorizam" (12/de julho de 1989).

Para nossa argumentação, é importante precisar o conceito de memória e qual relação se está articulando entre história, memória nacional/afetiva. Partimos do pressuposto que a relação entre história e memória é dinâmica e produtiva, de modo a redirecionar as relações entre imagens domésticas e públicas, na sua dimensão política (POLLACK, 1989, DELEUZE, 1990, DIDI-HUBERMAN, 2003). Se o cinema muitas vezes explora 
a memória histórica com o intuito de oferecer a ilusão de um passado que já teria terminado, portanto consumado e completo, outras vezes, ele atenta para as zonas de sombra entre as representações do passado, convidando o espectador a explorar esses acidentes visuais através de novas conexões entre imagens, espaços e tempos, a imaginar não o que foi, mas o que poderia ter sido.

O interesse pela história e a memória dos anos da ditadura tem vários efeitos sobre o contexto cinematográfico atual. Uma atenção renovada pelas imagens de arquivo e pelo testemunho é um deles. Certa visão da história e da filosofia tem muito a nos ensinar sobre a questão das imagens na sua relação com a memória e a história. Por isso, centrar-nos-emos agora sobre as noções de imagens de arquivo, história performada e testemunho na prática de alguns historiadores e filósofos para verificar relações possíveis com os procedimentos dos cineastas da década de 1980 e da última década.

\section{A imagem-performada e a expansão dos sentidos}

O historiador da arte Georges Didi-Huberman enfatiza que toda imagem de arquivo é um campo de conflitos, sempre passível de novas leituras e que nunca lidamos com apenas uma imagem, que em cada imagem há sempre um mínimo de complexidade. Para despertar as virtualidades adormecidas nas imagens, insiste, não se pode ignorar a necessidade de um trabalho que faz agir uma imagem sobre a outra, um trabalho de montagem que opera por fusões e colisões. Esse conhecimento por montagem exige uma outra relação com a imagem onde é preciso rejeitar os paradigmas da inteligibilidade causal e criar a possibilidade de um desvario. Aceitar que a imagem não é um campo de conhecimento fechado, que é centrífuga, perturbadora.

Trata-se de um trabalho, porque as imagens estão condenadas desde sempre a fazer a mediação entre o que foi e o que será. "É preciso parar diante do tempo [da imagem] (...)", afirma em Devant le temps (2003, p. 13). Essa pausa se explicaria porque diante da imagem estamos diante de um tempo que não é o das datas, sem linearidade, que não é exatamente o passado, mas que é atravessado por sobrevivências, espectros. Essa parada implica um desejo de humanizar e configurar o próprio tempo, de assegurar sua transmissão, de devotar a ele suas impurezas intrínsecas (ibid., p. 37). Para DidiHuberman, tal desejo configuraria o tempo da memória.

Se as imagens são portadoras de múltiplas tensões, a montagem seria uma das respostas a esse problema da construção da historicidade quando não está orientada pela ideia da sucessão de acontecimentos e pode, portanto, proporcionar às imagens uma válvula de escape das teleologias. A montagem nos ofereceria outra imagem do tempo, ou consciência do tempo, para Poivert (2007), fazendo explodir a narrativa da história e a disposição das coisas. Passamos do problema da imagem e seus esquemas iconográficos para, segundo Poivert, a questão da montagem como modo de performar 
a história, permitindo àquele que monta (cineasta, artista, historiador) experimentá-la de diferentes modos. Assim como a nova história teve de afrontar o positivismo, acredita, os historiadores contemporâneos têm um novo demônio pela frente, "o da fábrica incessante dos fatos midiáticos", de modo que nenhuma abordagem histórica pode nos preservar dessa dimensão imagética contemporânea (2007).

As imagens de arquivo, como os testemunhos, não devem ser entendidos como provas para validar ou contradizer um saber histórico, ao contrário; ao reconhecermos neles suas fragilidades e lacunas, ao aceitarmos o que não é evidente e/ou intencional, podemos fazer uma história descontínua, uma história que desarranja as representações que os acontecimentos produzem em nós. É a partir dessa perspectiva que a historiadora Sylvie Lindeperg explora as mudanças provocadas no olhar portado sobre uma imagem em função da passagem do tempo.

Se cada imagem carrega diversas camadas, temporalidades e estratos, é porque tais marcas se imprimem tanto no momento da tomada quanto no(s) momento(s) de sua retomada, ou seja, na sua imprevisível trajetória. O procedimento para tornar essas imagens visíveis ao olhar consistiria em cavar a superfície do filme/da fotografia para perceber as marcas da sua construção e de seus diferentes usos ao longo do tempo. "Na imagem, o registro do acontecimento pode preceder a sua compreensão e nela podem existir elementos não escolhidos que permanecem esperando para que sejam desvelados e interpretados" (LINDEPERG e COSMOLLI, 2008, p. 12). Deter-se diante de uma imagem seria levar em conta a história dos olhares, que se constitui em torno dela, atentar para o que está inscrito nos corpos dos atores e das testemunhas do acontecimento filmado.

É nessa mesma linha de reflexão que pesquisadores como Sylvie Rollet e Michel Poivert, ao se debruçarem sobre a noção de acontecimento histórico, retiram das imagens e do testemunho sua função de atestação. Se a proposta de Poivert é performar a história através de novas articulações de imagens que passam, portanto, a se impor como operadoras do acontecimento, para Rollet, o desafio é colocado ao espectador que deve organizar o olhar de modo também operatório diante dos arquivos audiovisuais.

Em suas pesquisas, Rollet investiga as estratégias expressivas que o cinema encontrou para evocar catástrofes que não possuem imagens (os genocídios durante a Segunda Guerra, na Argélia, no Camboja) e analisa o que há de intransmissível no procedimento da performance dos corpos, da repetição de gestos daqueles que viveram um evento brutal e que estão impossibilitados de compartilhar suas experiências pela fala. É na teatralização dos corpos, na recomposição de gestos do passado, que emerge a imagem-testemunho (ROLLET, 2011, p. 41).

Não se trata de repetir/atestar o que foi, mas favorecer a expansão dos sentidos, das percepções, da memória. Teatralizar a história através do corpo no documentário seria, portanto, colocar em xeque a crença de que a imagem nos distancia de uma relação com o mundo; ao contrário, ao teatralizá-la, exalta-se a possibilidade de olhar a história de novo, trazer posicionamentos variados e considerar seus efeitos no presente. 
Recuperar esses argumentos e conceitos é afirmar que, seja em filmes como Jango, Cabra marcado, Que bom te ver viva ou, nos mais recentes, como Os dias com ele, Uma longa viagem, Diário de uma busca, o que está em disputa - através do testemunho, da imagem de arquivo, da teatralização dos corpos - é o acontecimento da ditadura no Brasil, uma contenda em torno do território das imagens - do cinema, da internet, da TV -, pois é nele que se dá toda e qualquer disputa nos dias que correm.

\section{Da atestação à teatralização da imagem}

Ambos os filmes de Murat trabalham com imagens de arquivo e testemunhos e, ainda, com atores que interpretam papéis - a atriz Irene Ravache, como réplica da cineasta e das personagens entrevistadas, em Que bom te ver viva, e o ator Caio Blat como duplo do irmão da cineasta, em Uma longa viagem. Este último explora modos muito diferentes de resistir à ditadura brasileira, todos eles no interior de uma mesma família, nesse caso, da própria cineasta: a resistência pelo trabalho social (o irmão mais velho de Lucia, Miguel Murat); o confronto armado e a prisão (a própria cineasta), a adesão à contracultura (o irmão caçula, Heitor). Três opções que não só dizem respeito às formas pelas quais cada um dos três enfrentou os anos de ditadura, mas que também mostram o espectro das formas possíveis de resistência em tempos difíceis.

A morte recente de Miguel é o ponto de partida do filme. Enquanto Lúcia passou parte dos anos 1970 atrás das grades, por seu engajamento político, e Heitor viveu um desbunde lisérgico pelo mundo, Miguel se tornou uma espécie de esteio da família, estudou e formou-se em medicina. Os pais de Lúcia, com receio de que Heitor também entrasse na luta armada, enviam o rapaz para Londres. Na Europa, ele vira uma espécie de mochileiro nômade, experimentando diversos alucinógenos, narrando experiências através das cartas para a mãe, mandando presentes.

Interessa ao filme a trajetória de Lúcia e, sobretudo, a longa viagem de Heitor. Reencena-se o gesto de escrita das cartas e a vivência errante através de uma cenografia teatral, de um corpo (de Caio Blat) que atualiza sensibilidades, do uso de imagens projetadas de tempos e lugares diversos e, uma única vez ao longo do filme, dividindo a tela em dois: do lado esquerdo, o ator, do lado direito, o irmão. Heitor fala da viagem de ônibus de Mazar-e Sharif para Cabul, da neve avassaladora, do para-brisas que não funcionava, das mãos dos viajantes que limpavam os vidros do ônibus. O plano do ator entra então, do lado esquerdo da tela, e ele repete o mesmo depoimento de Heitor, as falas se sobrepõem as mesmas pausas, os mesmos gestos, o mesmo movimento do corpo. 


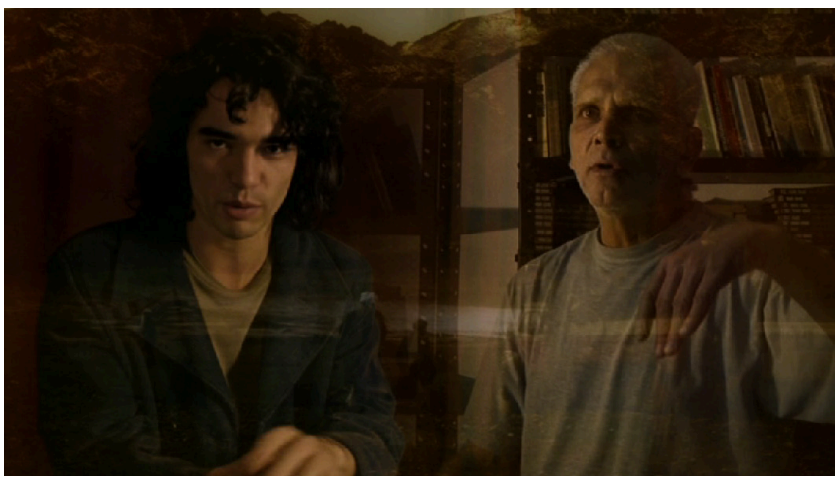

Fig.2. Uma longa viagem (Lucia Murat)

O procedimento de duplicar, na mesma cena, os rostos, as falas, as lembranças busca compreender de que modo os gestos (o duplo Caio Blat/Heitor) no cinema são capazes de transformar conceitos do paradigma representacional em conceitos que reabilitam o espaço da cena enquanto lugar de performatividade. Heitor fala com dificuldade, gagueja, sua dicção está um tanto prejudicada pelo uso de medicamentos para a esquizofrenia. Ao corpo duplicado dele (do ator, portanto) projetam-se imagens das cartas manuscritas, de filmes em Super-8, de registros diversos que marcam esse corpo com vivências, estados de espírito, experiências.

Como se essas imagens bruxuleantes trouxessem uma potencialidade original ao Heitor jovem/Caio Blat, permitindo a ele(s) e ao filme a atualização do que existe em estado virtual em ambos e no tempo impuro da memória. Se o duplo não é nunca o desdobramento do Um, mas a reduplicação do Outro (DELEUZE, s/d, p. 132), não é que o ator seja um duplo de Heitor simplesmente, mas é Heitor que encontra, através do filme, o outro nele mesmo.

Mais do que isso, para além da delimitação estreita do testemunho como copresença da testemunha e do acontecimento, é a relação de testemunho do espectador solicitada pelo filme que está em jogo através das sobreposições de imagens, tempos e corpos (ROLLET, 2011, p. 240). As imagens de arquivo projetadas sobre o corpo do ator configuram a potência transformadora do tempo da memória, lançando o espectador em um espaço de fabulação e montagem.

A tela dividida em dois explicita essa lacuna - própria ao tempo da memória, ao domínio das imagens - e ainda nos faz pensar na dimensão fabuladora do testemunho, na "autenticidade" da fala do ator tensionada pela "legitimidade" da fala de Heitor. Se as distinções entre o que é encenado e o que é real são explícitas, a tela dividida mostra que aquilo que seria da ordem da "atestação" e do "verdadeiro" (o relato testemunhal) pode se transformar, reinventar-se, que ao invés de negarmos à fabulação sua possibilidade 
de vínculo potente com o testemunho, podemos ver nessa aliança um caminho para repensar a imagem e o paradigma representacionista. Se "o testemunho está sempre relacionado pelo menos com a possibilidade da ficção, do perjúrio e da mentira" (DERRIDA apud SELIGMANSILVA, 2008, p. 71), eliminar a possibilidade da ficção é elidir o sentido mesmo do testemunho, desconsiderar que tal ato significa não apenas contar histórias, mas reiterar sua crença no presente ao oferecer seu corpo e sua vida ao outro. Assim é que a tela, o relato das viagens e o corpo duplicados pelo filme explicitam a paradoxal singularidade do testemunho, ao mesmo tempo único, insubstituível, e repetição, passagem - para a ficção, o cinema, a imagem.

A questão fundamental da transmissão do acontecimento, apesar de tudo (BENJAMIN, 1987), está, portanto, assegurada através dessas clivagens interiores à imagem, ao corpo e ao testemunho. Se Heitor fala com dificuldade, seu senso de humor e perspicácia continuam intactos. Nesse sentido, os experimentos e as situações bizarras vividas por ele no passado ganham espessura sensorial, plástica e perceptiva quando Caio Blat interage com as imagens projetadas - sobre livros e superfícies diversas - de lugares por onde Heitor passou (Irã, Afeganistão, Índia, EUA...).

Em certo momento, vemos a imagem de uma paisagem projetada sobre uma folha de papel. Somos então surpreendidos pelo jovem poeta Chacal que surge correndo na direção da câmera, dá um salto e passa pelo plano. Blat, no mesmo instante, repete o gesto de saltar do poeta. Ele transpassa num arroubo o papel-tela e, correndo na direção do espectador, sorri. Tais imagens projetadas dizem respeito às performances de Chacal, em Ok vc KO (1973), poema de contestação política, filmado em Super-8 pelos artistas plásticos Luciano Figueiredo e Oscar Ramos nas ruas de Londres onde viviam; tais imagens solicitam a performance de Blat.

O lugar testemunhal do espectador se constrói então entre a narração de Lucia Murat e os fragmentos projetados de cartas manuscritas, postais, fotografias, filmes que, como lampejos, interrompem a linearidade de uma possível história daqueles que sobreviveram à ditadura e despertam, no espectador, novos modos de percepção da imagem (de arquivo), do corpo (o duplo Blat/Chacal) e do espaço da cena.

A atuação de Blat devolve a existência das memórias do corpo (Heitor/Chacal) e preenche criativamente a ausência de imagens daqueles que resistiram à ditadura, forjando para si uma vida hippie, mística, errante; o espaço cênico torna-se o combustível desse tempo impuro da memória da contracultura, onde a liberação do corpo viria a ser uma alternativa tão subversiva quanto a militância de esquerda no Brasil.

O tempo da memória se teatraliza como imagem, ao mesmo tempo que a imagem tem cada vez mais ressaltada sua dimensão de acontecimento - performativo, perceptivo, sensorial. Parte do documentário brasileiro recente, nesse sentido, tem explorado uma figuração que avança da atestação para a teatralização, transformando os testemunhos e as imagens de arquivo menos em lugar de verdade do que em instrumentos para performar, retomando Poivert, sensações daquela experiência política.

Se o modo de operar com as imagens é bastante distinto em Que bom te ver viva, Cabra marcado ou Jango, importa a tarefa ideológica que assumem no sentido de 
querer preservar uma certa leitura da história do país - seja dos torturados pelo regime, dos explorados economicamente, de líderes políticos específicos. O Golpe Militar inaugura uma sucessão de derrotas, de personagens vencidos, de reformas colapsadas que englobam a organização das ligas camponesas no interior do país (Cabra marcado) ou a trajetória de líderes políticos antes e depois do Golpe Militar (Os anos JK, Jango). Os documentaristas, nesse momento, se vêem incumbidos de resgatar a memória e a história do país pela ótica dos derrotados, tensionando a cultura da "conciliação" forjada pela transição democrática.

Se em Que bom te ver viva, a disputa pela memória da história se dá pelo uso das imagens de arquivo (as manchetes da Folha de São Paulo e Jornal do Brasil com pedidos de prisão e pena de morte para "guerrilheiros" e "terroristas") e dos depoimentos como meios para atestar um passado violento, o papel da atriz Ravache no espaço cênico em torno da mesa, ao trocar de lugar (de sujeito e de fala), restitui a possibilidade de um corpo sobrevivente capaz de sorrir, ironizar, ter desejos; mas, ainda aqui, trata-se de uma teatralização engessada, cuja função apenas reitera o topos de janela aberta para a história do país, fixando sentidos para o passado. Em outras palavras, o filme aposta em uma mirada retrospectiva para tais lutas e dores, legitimando as ações daqueles que outrora pegaram em armas e corroborando os testemunhos com sua evidência indicial.

Em Uma longa viagem, a duplicação defasada dos movimentos e da fala de Heitor, diferentemente, põe o espectador em posição e recoloca sua relação com a imagem, com o espaço cênico, com a memória histórica. A imagem duplicada no interior da cena explicita a difícil dinâmica das relações entre memória e história, imagens domésticas e públicas. Trata-se de uma topografia da cena que constrói uma relação dialógica entre esses pares, tornando sensíveis os modos de experimentar as imagens, a montagem, o tempo. Um teatro da memória que surge não para suprir as lacunas próprias às imagens e ao testemunho, mas para deixá-las em aberto (a errância e as drogas teriam sido uma alternativa política ao golpe e à luta armada?), de modo a devolver à imagem ficcional sua potencialidade para se tornar imagem documental, testemunhal (COMOLLI, 2002).

Em Uma longa viagem, a imagem revela ser um trabalho de memória que na sua leitura afetiva e pessoal do passado rearranja as representações que a história produz em cada um. O filme recupera, portanto, a questão da memória política do país, cara aos documentários dos anos 1980, porém na chave de um corpo e de uma imagem performados, de uma singularidade encarnada, cara à produção contemporânea.

\section{O espaço da cena, a atuação}

Armar uma cena dentro da cena do filme permite explorar novas conexões com o passado, liberar singularidades não visadas no acontecimento original, explicitar que a teatralização pode fazer experiências de tal densidade que eventualmente irriga a própria epistemologia da história. Certamente o lugar assumido pela teatralização, justamente pela particularidade que esta pressupõe, deve ser discutido na análise de cada obra, 
sendo equivocada qualquer crença a priori em uma qualidade genérica intrínseca à dimensão performativa no documentário.

Se a teatralização redimensiona criticamente as imagens documentais na sua relação com a referencialidade, sendo, portanto, tão ou mais multifacetada nos seus sentidos do que o fato que the deu origem (BANGMA, 2005), ela também pode funcionar como atestação do passado, atenuando sua dimensão reflexiva em prol de uma asserção coesa.

Em Uma longa viagem, a teatralização da imagem (de $O k$ vc KO) e da história daqueles que viveram a experiência do exílio revela substratos de uma memória latente, nos anos 1960/1970, condicionado pelas drogas e pela adesão à contracultura. Duplicar, no interior da cena, os gestos do filme experimental $O k$ vc KO e os depoimentos de Heitor é um recurso expressivo que - ao contrário de preencher as lacunas do tempo histórico, de completar o extracampo - multiplica fibras de tempo (de lembranças, imaginários, desejos), de modo a performar a memória e a história das formas possíveis de resistência. Em Que bom te ver viva, diferentemente, o recurso da teatralização vem em socorro dos depoimentos, julgados insuficientes para dar conta do que passou, de modo que a performance de Ravache está ali para completar os extracampos, ajustar as falhas do que é lembrado, restituindo ao espectador um domínio mais pleno da experiência da luta armada e da tortura.

Em Uma longa viagem, a teatralização duplicada, seja da cena do testemunho, seja da cena do filme em Super-8, instala uma crise de sentido nas representações, convocando o espectador a investir de forma reflexiva no espaço-tempo do filme. O contraste com a imagem-atestação de Que bom te ver viva deixa patente os deslocamentos entre uma memória histórico-política coesa, dos vencidos, e outra em aberto, afetiva, que parte de uma ausência íntima (o irmão) para performar a história de uma geração que viveu os anos 1960/1970 sob a forma de rompimento radical com tudo.

Partir de uma ausência íntima (de um irmão, um pai) parece ser uma característica de boa parte da produção documental recente. À falta de imagens, de documentos, de verdade, soma-se a lacuna íntima. Em Os dias com ele, a cadeira vazia atualiza as tensões entre a recusa de performar do pai e a necessidade de performar da filha. O espaço da cena é então convocado, pela teatralização, a redimensionar as relações entre a interrupção do que se pode saber (as lacunas do tempo) e a interrupção do passado espectral (a imagem teatralizada da ausência).

Andrea França Martins é professora do Programa de PósGraduação do depto de Comunicação Social da PUC-Rio e pesquisadora do CNPq.

afranca.pucrio@gmail.com

Patricia Machado é doutoranda na UFRJ.

patricia.furtado.machado@gmail.com 


\section{Referências}

AZEREDO, E. O denso elogio da sobrevivência. Segundo Caderno, O Globo, p. 3, 1989.

BANGMA, A. Experience, Memory and Re-enactment. Berlin: Revolver Publishing, 2005.

BENJAMIN, W. "Conto e cura". In: Obras escolhidas II. São Paulo: Brasiliense, 1987.

COMOLLI, J. L. "El espejo de dos caras". In: Imagen, política y memoria. Buenos Aires: Libros des Rojas, 2002.

DELEUZE, G. A imagem-tempo. São Paulo: Brasiliense, 1990.

Foucault. Lisboa: Veja, s/d.

DIDI-HUBERMAN, G. Devant les temps. Paris: Les Editions de Minuit, 2003.

ESCOREL, E. O que passou, passou? Caderno Idéias. Jornal do Brasil, p. 9, 1989.

FRANÇA, A. É possível Conhecer a Estória Toda?. In: FURTADO, B. (org.). Imagem Contemporânea. São Paulo: Hedra, 2009. 2 v.

GAGNEBIN, J. M. O preço de uma reconciliação extorquida. In: TELLES, E.; SAFATLE, V. (orgs.). O que resta da ditadura. São Paulo: Boitempo, 2010.

LINDEPERG, S.; COMOLLI, J. L. Images d'Archive: I'emboîtement des regards (entretien). In: Images Documentaires, n. 63, 2008.

POIVERT, M. L'Événement comme expérience: les images comme acteurs de l'histoire. Paris: Hazan, Jeu de Paume, 2007.

POLLACK, M. Memória, esquecimento e silêncio. Estudos Históricos, Rio de Janeiro, v. 2, n. 3, 1989.

ROLLET, S. Une ethique du regard- Le cinema face à la Catastrophe d'Alain Resnais à Rithy Panh. Paris: Hermann Editions, 2011.

SELIGMANN-SILVA, M. Narrar o trauma - a questão dos testemunhos de catástrofes históricas. Psic. Clin., Rio de Janeiro, v. 20, n. 1, p. 65-82, 2008, Disponível em: <http://www.scielo.br/pdf/pc/ v20n1/05.pdf>. Acesso em: jul. 2013. 